\title{
The development of effective ruminant breeding programmes in Ireland from science to practice
}

\author{
D.P. Berry ${ }^{\dagger}$, F.L. Dunne, N. McHugh, S. McParland, A.C. O’Brien, A.J. Twomey
}

Teagasc, Animal \& Grassland Research and Innovation Centre, Moorepark, Fermoy, Co. Cork, P61 P302, Ireland

Abstract

A genetic improvement programme is a sustainable, cumulative and permanent approach to achieving year-on-year performance gains. Its success is predicated not only on an efficient and effective breeding programme but also on a vision of the traits of importance in the future. A single, industry-owned, centralised database for cattle and sheep has been the foundation for genetic improvement programmes in Ireland. While DNA information has been heralded as a breakthrough for accelerating genetic gain, the basic principles of a successful animal breeding programme still remain the same: (1) a pertinent breeding goal, (2) the appropriate breeding objective to deliver on the breeding goal, (3) an accurate genetic evaluation system, (4) an efficient and effective breeding scheme, and (5) a system to disseminate the elite germplasm to the end user; also of importance is a system for validating the underlying procedures and principles. The constituent traits and their relative emphasis within breeding objectives will continue to be contentious. Traits that will need to be considered more in future ruminant breeding objectives include environmental impact, product quality and animal well-being, including health; while not always explicitly included in Irish breeding objectives for cattle and sheep, indirect improvements for many are expected via the genetic improvement in traits like reproductive performance and survival as well as macro measures of quality such as milk fat and protein concentration and carcass merit. Crucial for the future sustainability of ruminant production systems is the co-evolution of management systems and breeding programmes so that the animal of the future is suited to the most sustainably efficient production system.

Keywords

Breeding programme $\cdot$ genetic $\cdot$ heritability

\section{Introduction}

Genetic improvement has been documented to contribute up to $90 \%$ of the gains in performance in livestock over time (Havenstein et al., 2003); in reality, however, in ruminant production systems this is more like $50 \%$ (Berry, 2018). The cumulative, permanent and sustainable characteristics of genetic improvement dictate that benefits culminate over generations and the benefits that accrue can be permanent. On the other hand, any unfavourable trends realised through breeding, if not addressed, can deteriorate further with each advancing generation. An example of the latter in ruminants is the erosion of reproductive performance in both dairy and beef cattle (Lucy, 2001; Berry et al., 2016a) as a consequence of aggressive selection for milk production and terminal characteristics, respectively. Such deterioration remains a threat especially for animal features not routinely measured (e.g. lifetime efficiency of feed use, environmental hoofprint). Projected genetic trends must also consider the production system (e.g. grazing or total mixed ration [TMR]) required to meet the demands of the ruminant; hence, the management systems and breeding programme must co-evolve.

The steps in a successful breeding programme are graphically illustrated in Figure 1 (adapted from Lopez-Villalobos \& Garrick, 2005). The fundamentals of a successful breeding programme are to mate genetically elite individuals so that the next generation will, on average, be superior to the current generation; consideration must also be given to minimising the relationship among parents so as to avoid a rapid accumulation of inbreeding. This is because as well as having repercussions for animal performance (McParland et al., 2007, 2008; Bjelland et al., 2013), inbreeding also tends to 


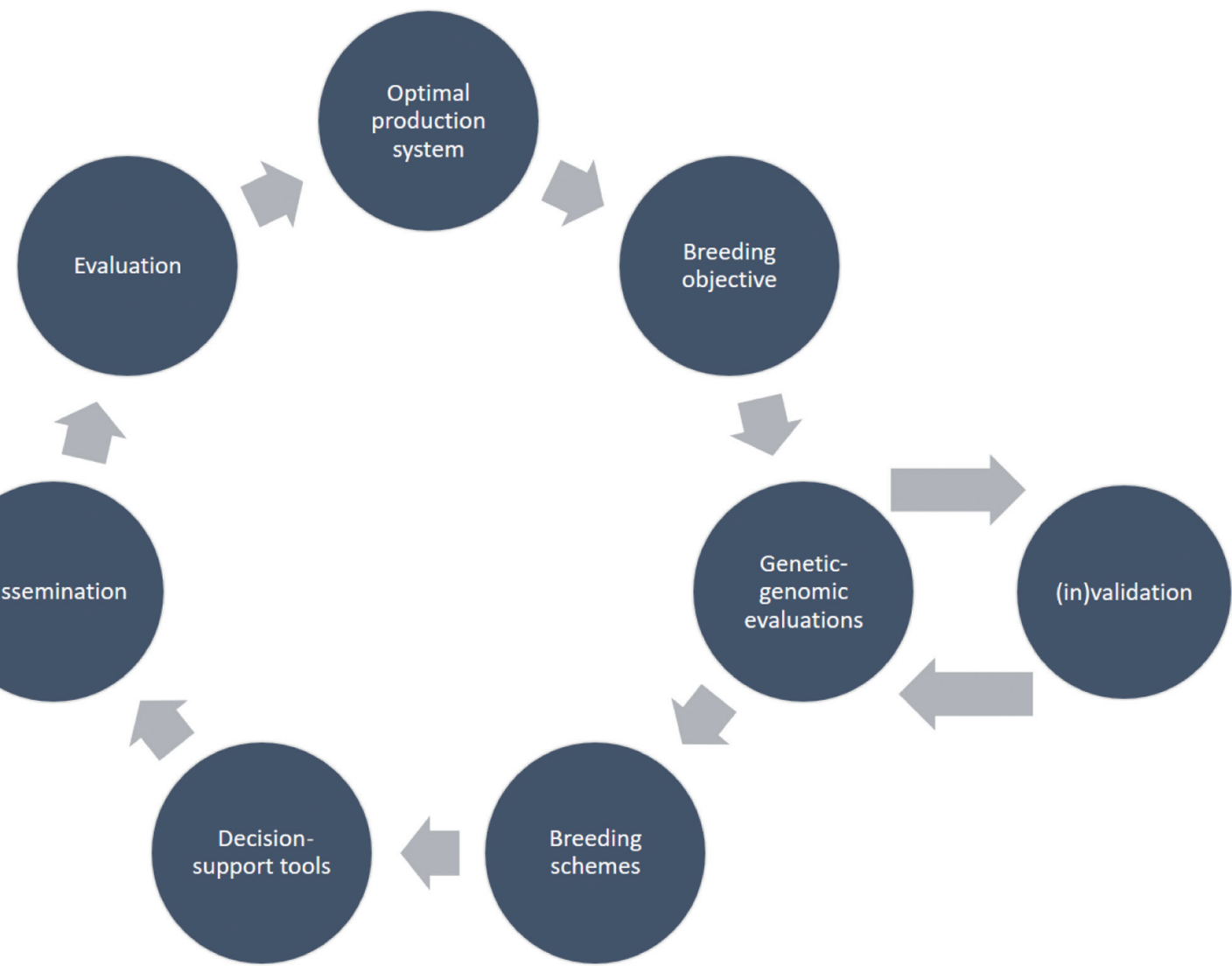

Figure 1. Components of a successful breeding programme.

erode exploitable genetic variability thus impacting long-term genetic gain (Berry, 2018). Validation of the benefit of genetic selection is required to instil confidence among end users thus ensuring high penetrance. This review focuses on the main scientific achievements that have contributed to genetic gain in Irish ruminant breeding programmes and the research undertaken to facilitate such performance gains; the review concludes with some thoughts on what gaps in knowledge currently exist, again with a particular attention on cattle and sheep breeding in Ireland.

\section{Main scientific advancements}

Genetic evaluations globally are generally based on a mixed model framework developed in the middle of the 20th century (Henderson, 1950). The best linear unbiased prediction procedure for predicting genetic merit of individuals does so by decomposing the observed performance of an animal (termed phenotype) into its genetic contribution, the contribution due to systematic environmental effects (e.g. herd, year, gender, age), and that remaining as unexplained variability (i.e. residual). Access to predictions of genetic merit for individuals enabled the exploitation of selection index methodology developed by Hazel (1943). Selection indexes are devised to maximise the correlation between animals ranked on the developed index and those ranked on an overall breeding objective. The breeding objective for a breeding programme is analogous to a mission statement for a company; it comprises a number of traits each appropriately weighted based on (perceived) importance. While observations for a given trait in a breeding objective are not necessarily required, data must exist for traits in the underlying selection index and thus much effort has been expended on strategies and the associated backend information and communication technology (ICT) infrastructure to capture and store such data.

While economic modelling is used to decide the weights on individual traits within dairy, beef and sheep breeding objectives in Ireland, some jurisdictions use economic modelling only as a guide with the final weights on individual traits often decided by a committee. Breeding objectives are routinely updated based on new information and knowledge both on the traits of likely importance in the future and on their associated (future) costs and value. Figure 2 demonstrates 


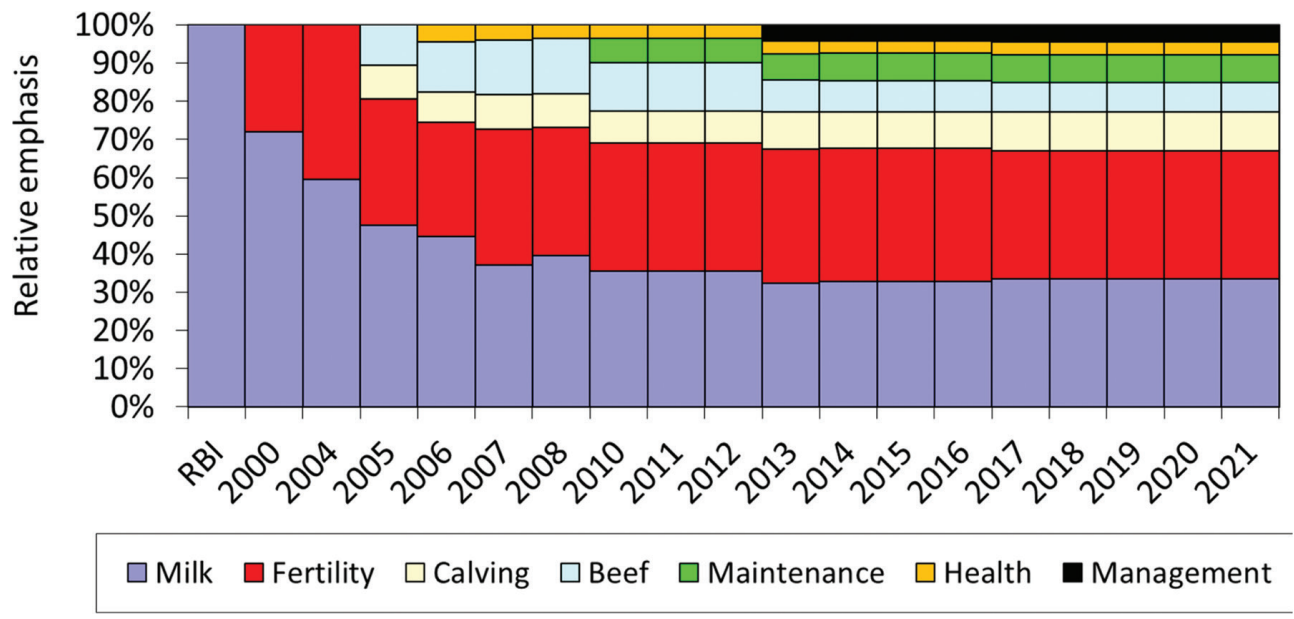

Figure 2. Change in emphasis on sub-indexes within the Irish dairy cow breeding objective, the economic breeding index (EBI) since its establishment in 2000; the relative breeding index (RBI) existed prior to 2000.

how the national dairy cow breeding objective in Ireland, the economic breeding index $(\mathrm{EBI})$, has changed since its introduction in the year 2000; the changes observed reflect the addition of new traits as genetic evaluations became available but also the updating of the economic values as the expected prices and costs of production changed (Berry et al., 2007). Because generation intervals tend to be particularly long in (dairy and beef) cattle (García-Ruiz et al., 2016), breeding objectives in cattle especially must be very futuristic.

Specific to the success of ruminant breeding programmes in Ireland was the establishment of the Irish Cattle Breeding Federation (ICBF) in 1997 (Wickham et al., 2012) followed in 2009 by the development of Sheep Ireland. The ICBF and Sheep Ireland are mandated by the Irish government to generate and distribute accurate national genetic evaluations to the respective industries. Prior to the establishment of the ICBF and Sheep Ireland, most stakeholders had their own system for data recording and storage, each with their own specific objectives but also potentially their own population demographics or geographical representations. For example, each cattle breed society herd book, of which there were 18 at the time ICBF was established, had its own computing system, while each milk recoding agency, of which there were 8 in 1998, also had its own computing system. Although creating a single version shared repository of verified data was an ambitious and arduous task for both the ICBF and Sheep Ireland, the developed infrastructure is now the epicentre of breeding (and many management) decisions made on Irish dairy, beef and sheep farms.

Annual genetic gain in any population for any trait or breeding objective can be easily represented by the breeder's equation (Rendel \& Robertson, 1950):

$$
\Delta G=\frac{i \cdot r \cdot \sigma_{g}}{L}
$$

where $\Delta G$ is annual genetic gain, $i$ is the intensity of selection, $r$ is the accuracy of selection or, in other words, the accuracy with which the genetically elite animals can be differentiated from the genetically inferior, $\sigma_{g}$ is the genetic s.d. (i.e. a measure of variability) and $L$ is the generation interval (i.e. the average age of the parents at the birth of their progeny who in turn become parents). Hence, most of the effort in animal breeding research and development has focused on the exploration of technologies and approaches to improve each metric. In fact, most of the focus among geneticists has been on improving the accuracy of selection. The accuracy of selection is a function of the heritability of the trait and the quantity of information available; this is true irrespective of whether based on traditional genetic evaluations or genomic evaluations. Information in this context traditionally implied usable phenotypic data from the animal itself, its ancestors or its descendants. In more recent decades, approaches to supplementing this (observed) phenotypic information with genomic (i.e. DNA) information have been explored (Meuwissen et al., 2001; Berry et al., 2009). Nonetheless, the accuracy of selection irrespective of whether based on traditional genetic evaluations that exploit ancestry, or genomic information to infer relationships, is still a function of the heritability of the trait (Figure 3); the lower the heritability, the greater the number of progeny records required to achieve a given accuracy of selection.

The heritability of a trait is a measure of the proportion of the observed (i.e. phenotypic) variability amongst individuals that can be attributable to genetic differences (Visscher 

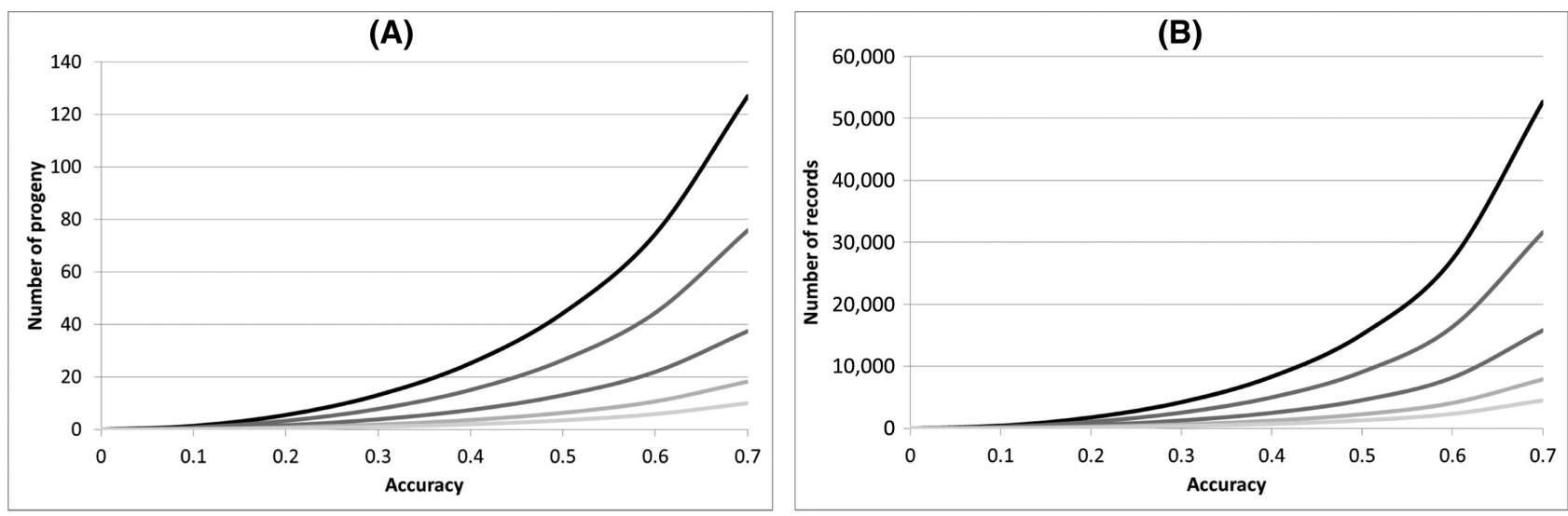

Figure 3. For heritability values of $0.35,0.20,0.10,0.05$ and 0.03 (in order of increasing darkness of lines), (A) the number of progeny required to achieve a given accuracy of selection using traditional ancestry-based genetic evaluations and (B) the number of records of phenotyped and genotyped animals to achieve a given accuracy of genomic evaluations (based on 1,000 effective chromosomal segments and $80 \%$ of the genetic variance accounted for by the genotyped markers). Note reliability which is used in cattle in Ireland is the accuracy squared.

et al., 2008), the latter usually being confined to differences that are directly transmissible from one generation to the next (i.e. additive genetic effects). All else being equal, the higher the heritability, the greater the accuracy of selection from traditional evaluations but also the fewer the number of genotyped and phenotyped animals required for a genomic evaluation reference population (Figure 3); nonetheless, high accuracy of selection can be achieved even for low heritability traits, and thus heritability has minimal impact on genetic gain in an efficient and effective breeding programme. Having said that, heritability is important for traits that are resource intensive to measure which is a likely feature of traits growing in importance in ruminant production systems such as environmental impact, product quality and animal well-being. Genomic selection (Meuwissen et al., 2001) using genotype information scattered densely across the entire genome has contributed to a transformational change in animal breeding programmes. This was particularly true for those species with long generation intervals and that assign considerable selection pressure to low heritability traits measured only in one sex; such characteristics typify modern dairy cow breeding programmes which, when coupled with the predominance of only one dairy breed in most temperate regions (i.e. Holstein-Friesian), is the reason for the rapid and ubiquitous uptake of genomic evaluations in dairy cattle. Whereas maternal breeding objectives in beef and sheep suffer also from comprising low heritability traits measured only on older females, traits constituting a large emphasis in the terminal indexes tend to be highly heritable, measured early in life and not sex limited. Genomic selection was an advancement on the previously advocated marker-assisted selection; the latter relied on just a few genetic markers but failed to deliver on promises of vastly improved accuracy of selection for quantitative traits across the population. The heralding of genome-wide enabled selection was possible with the commercial availability of (relatively) low-cost genotyping platforms (Boichard et al., 2012; Judge et al., 2016) that could rapidly and reproducibly (Berry et al., 2016c; Purfield et al., 2016; Marina et al., 2021) genotype animals simultaneously for tens of thousands of genomic variants. Ireland was the second country in the world to officially release national genomic evaluations in dairy cows (Berry et al., 2009) and the first country to release national genomic evaluations in a multi-breed population of beef cattle (Berry et al., 2016b); national multi-breed genomic evaluations for sheep now also exist in Ireland. Ireland also developed its own bespoke cattle genotyping platform, optimised in content for the Irish dairy and beef population while still being compatible with other commercially available platforms (Mullen et al., 2013); included on the Irish bovine genotype panel are variants to enable genomic evaluations and parentage testing among putative parent-offspring pairs genotyped using different variant types (McClure et al., 2013), as well as variants located within major genes (including those conferring congenital defects) and variants of research interest. Genomic variants included on the ovine panel are those to enable genomic evaluations and parentage testing/discovery as well as including several causal mutations and putative causal mutations associated with performance metrics.

\section{Irish national cattle and sheep breeding objectives}

The suite of traits included in Irish national dairy, beef, beefon-dairy and sheep breeding objectives in 2021 is shown in Figure 4, along with their respective relative emphasis. The 


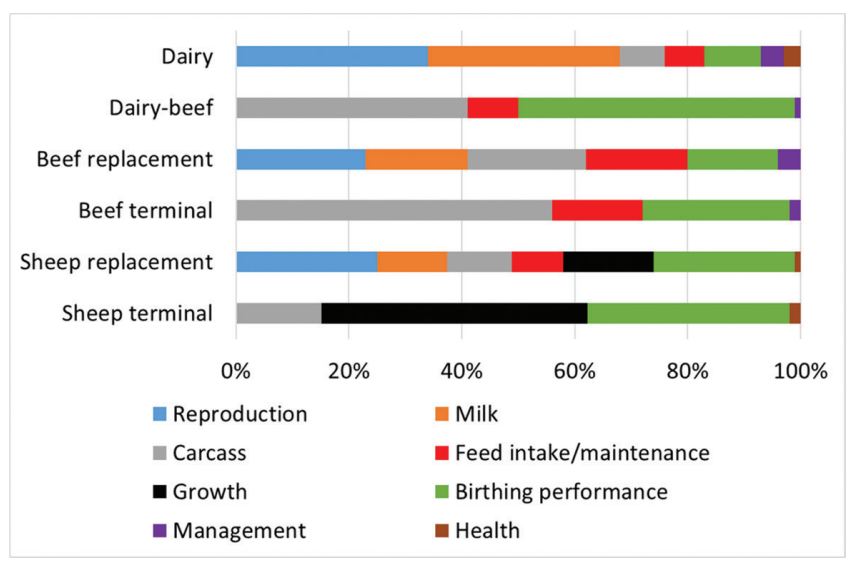

Figure 4. Relative emphasis on suites of traits within the Irish dairy and dairy-beef indexes as well as the beef and sheep replacement and terminal indexes.

partial correlation (i.e. adjusted for breed) among the beef terminal, beef replacement and dairy-beef index in 918 highreliability artificial insemination $(\mathrm{Al})$ beef bulls with progeny in Ireland is $0.40-0.41$. The partial correlation between the sheep terminal and replacement index in high accuracy rams is 0.41 .

Reproductive performance including survival constitutes a large proportion of the relative emphasis within the different breeding objectives targeting female replacements ranging from $23 \%$ emphasis in beef to $34 \%$ emphasis in dairy (Figure 4); this is largely attributable to the importance of maximising the utilisation of grazed grass and realising mature animal performance, with reproduction being represented by the number of lambs born in sheep; no predictions of genetic merit exist for ewe survival in sheep, but this is an area of ongoing research. Both reproduction and milk production (represented by maternal weaning weight or growth in beef and sheep) combined represent 37\%, $41 \%$ and $68 \%$ of the emphasis in the sheep replacement index, the beef replacement index and the dairy breeding objective, respectively (Figure 4). The relative emphasis on calving or lambing performance (both direct and maternal) across all six breeding objectives was, on average, $27 \%$ varying from $10 \%$ in the dairy breeding objective to $49 \%$ in the dairy-beef index; calving performance here includes actual calving difficulty as well as both gestation length and perinatal mortality. Progeny slaughter performance represents just $8 \%$ of the emphasis in the dairy breeding objective but $12 \%$ and $21 \%$ in the sheep and beef replacement indexes; carcass traits (including age at slaughter for sheep) represent $41 \%-63 \%$ of the emphasis in the three terminal breeding objectives (Figure 4).

Fundamental to a successful breeding program, whatever the species, is routine access to high-quality data (with recorded ancestry and other ancillary information) for the traits of interest representing the germplasm being used in the population. Figures 5 and 6 illustrate the quantity of data recorded (including ancestry information) in Irish cattle and sheep populations, respectively. Two main points can be made - the extent of recording, especially in cattle, is very large and has been increasing in the past two decades and there is a relatively good recording of sire information, although room for improvement exists.

Genetic gain in s.d. units for each of the six breeding objectives is presented in Figure 7. Genetic gain in the sheep and beef breeding objectives was low (between 0.37 and 0.84 units) over the 20-yr period which is considerably slower than the genetic gain of 2.79 units for the national dairy index over the same 20 -yr period. Year-on-year genetic gain in dairy animals has been relatively constant each year since 2002 . Using the parameters proposed by Schaeffer (2006) for a successful dairy cow breeding program, a genetic gain of 0.215 genetic s.d. per year should be possible; this would increase to 0.47 for a successful genomic selection breeding program. Hence, genetic gain in the Irish dairy breeding programme is considerably less than what should be possible. Despite this, clear phenotypic differences between animals genetically divergent for the Irish dairy cow breeding goal (i.e. the EBI) are evident (O'Sullivan et al., 2019). In 2015, a DAFM-funded scheme used monetary incentives to encourage the use of the replacement index in beef herds which was then followed by the introduction of genomic evaluations in 2016 (Berry et al., $2016 \mathrm{~b})$. This has resulted in a genetic gain of 0.2 genetic s.d. units per year in the replacement index since the introduction of this scheme; this is similar to the annual genetic gain observed in dairy. Genetic gain was lowest for the dairy-beef index ( 0.17 units over the $20-y$ r period), which is an artefact of the dairy-beef breeding objective only being available to herd owners since 2019 (Berry et al., 2019). All in all, genetic gain has been achieved and the mass of validation studies undertaken to date which verify the impact of such genetic gain on phenotypic performance clearly imply that phenotypic gains have also been achieved.

Animal health continues to be poorly represented in the different breeding objectives, being only present in the dairy breeding objective (i.e. mastitis, somatic cell count and lameness) and both sheep breeding objectives (i.e. mastitis, lameness and dagginess); yet, the emphasis in all indexes is $\leq 3 \%$. Although currently not included in breeding objectives, stand-alone genetic evaluations for tuberculosis (Ring et al., 2019) and liver fluke (Twomey et al., 2016) in beef and dairy cattle are available nationally; further research is ongoing on increasing the suite of health traits with genetic evaluations.

The reasoning for the perceived low emphasis on health traits within the breeding objectives is because the definition of an economic value is the change in profit per unit change 
(A)

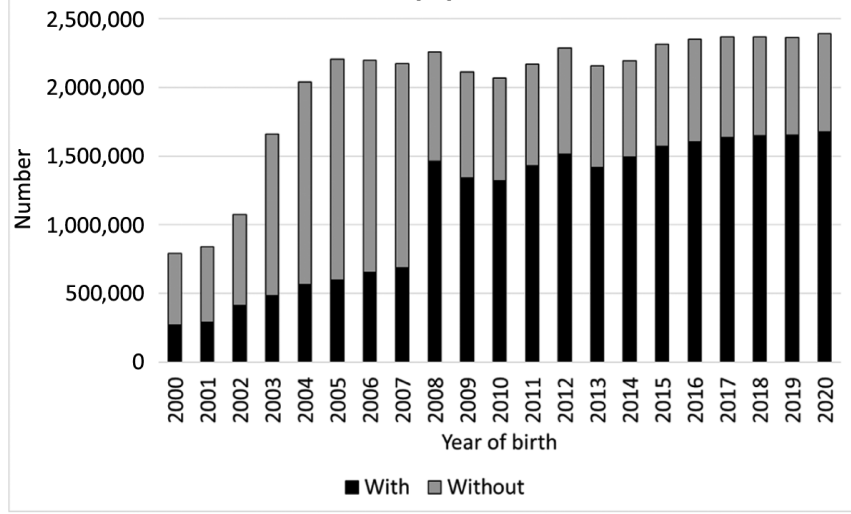

(C)

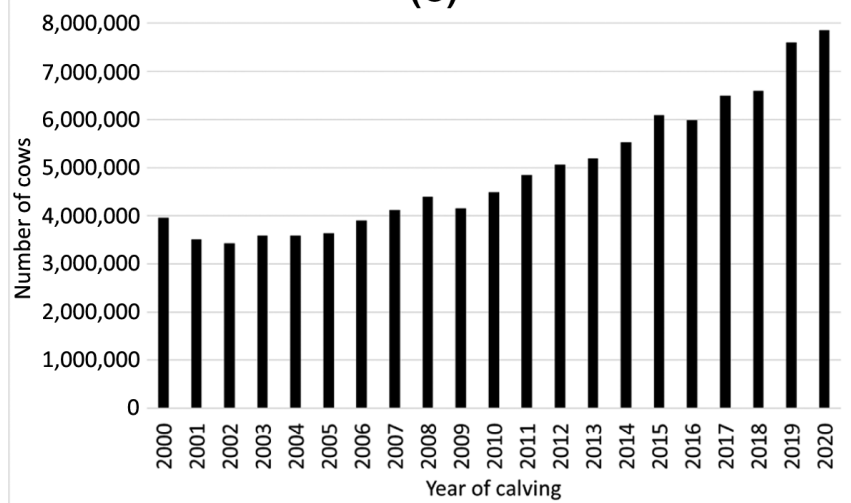

(B)

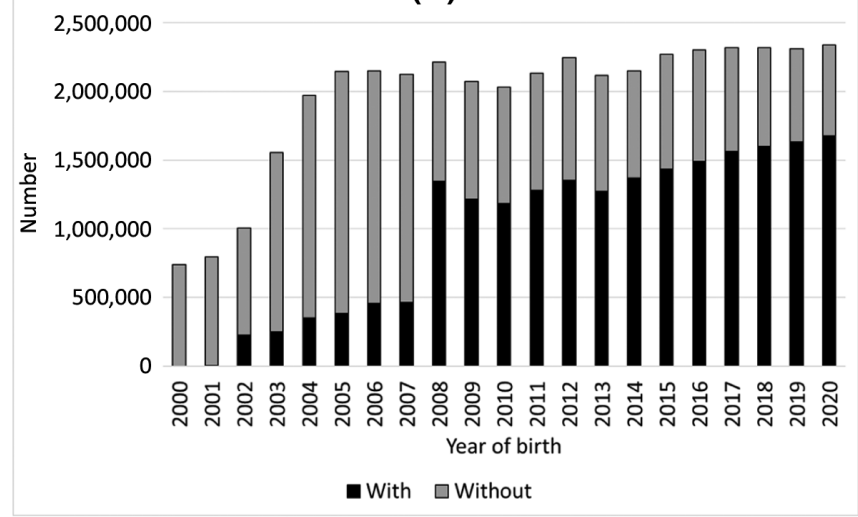

(D)

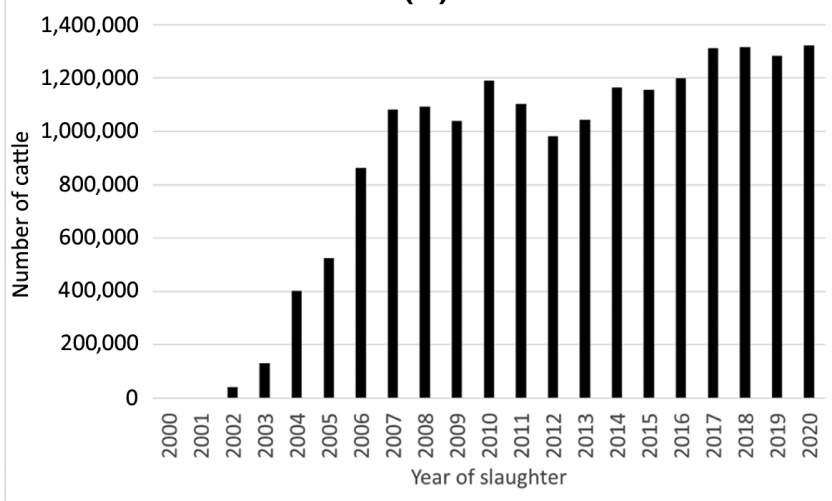

Figure 5. Number of (A) calves born with or without a sire recorded, (B) calving events with or without a recorded calving difficulty score, (C) dairy cows milk recorded and (D) prime cattle carcass records all recorded within the Irish Cattle Breeding Federation national database.
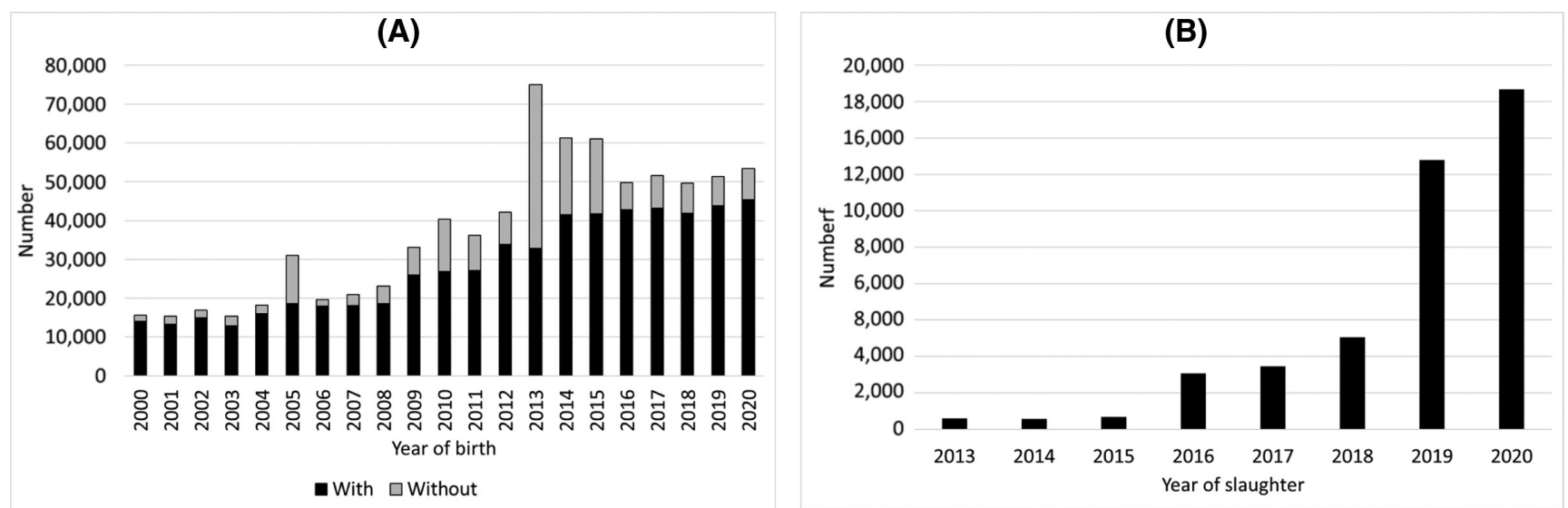

Figure 6. Number of (A) lambs born with or without a sire recorded and (B) lamb carcass records all recorded within the Sheep Ireland database. 


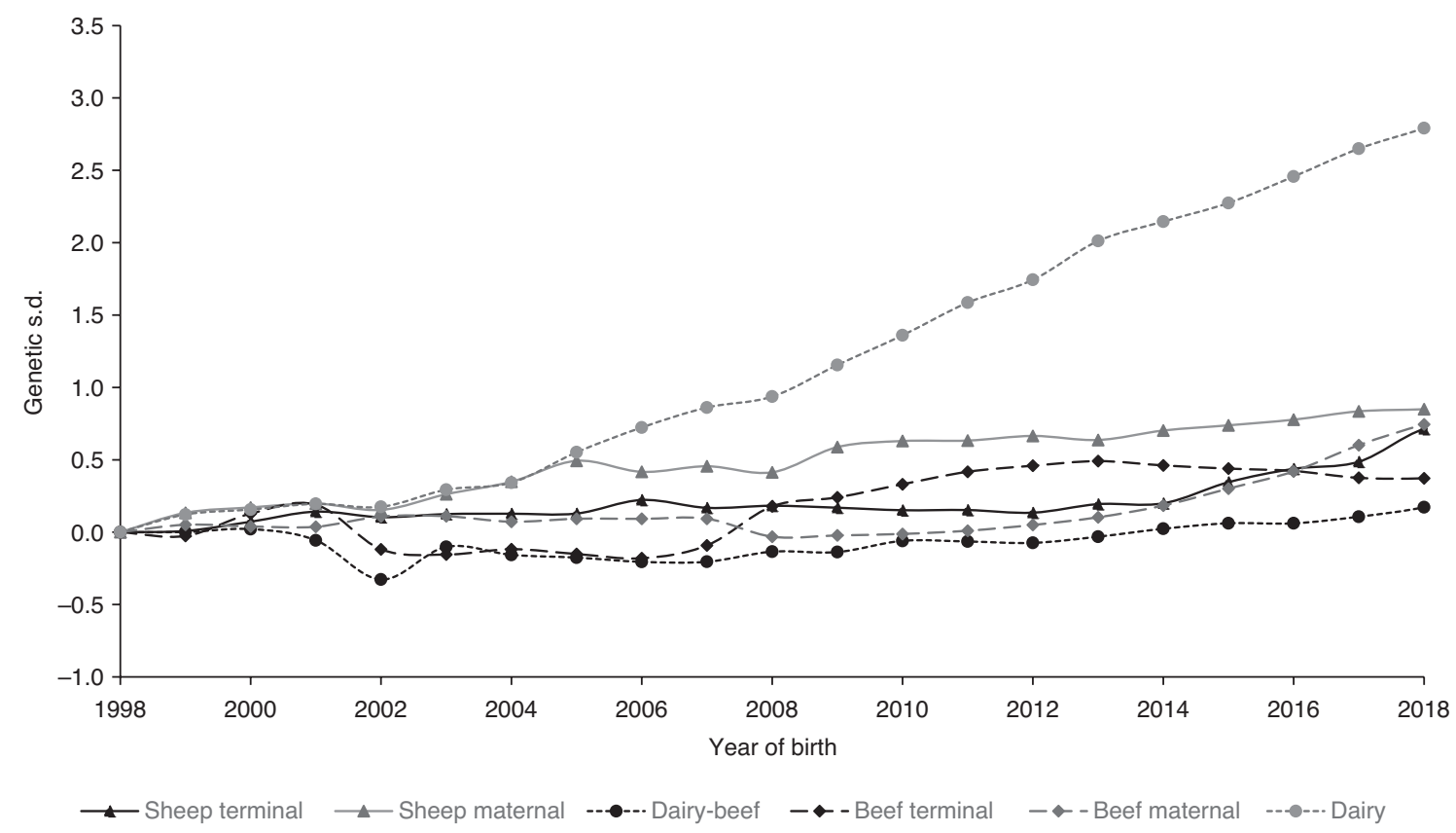

Figure 7. The genetic trend from 1998 to 2018 for the six breeding objectives in Ireland: sheep terminal index (triangles, solid black line; s.d. $=€ 0.65$ ), sheep maternal index (triangles, solid grey line; s.d. =€2.44), dairy-beef index (circles, dotted black line; s.d. =€21), beef terminal index (diamonds, dashed black line; s.d. $=€ 32$ ), beef maternal index (diamonds, dashed grey line; s.d. $=€ 40$ ) and the dairy index (circles, dotted grey line; s.d. = €67).

in the trait in question holding all other traits in the breeding objective constant. Compromised animal health is known to influence other performance metrics (Sayers, 2017). Hence, animals with a genetic predisposition to poor health (or whose descendants are more likely to succumb to poor health) are also likely to have substandard predictions of genetic merit for performance traits; thus, the breeding objective values of these animals will be penalised via their poor predictions of genetic merit for these performance traits. The definition of economic values is also pertinent when explaining how the change in emphasis on certain traits may differ from expectation as prices and costs change (Figure 2). For example, when milk price is predicted to reduce, there may be an expectation that the emphasis on milk production in dairy breeding objectives should increase in the pursuit of maintaining profit; however, the increase in profit per unit increase in the yield trait has reduced and thus the emphasis, in turn, reduces. Moreover, economic values do not consider the accuracy of selection. Given the low heritability of health traits (Pryce et al., 1997; Berry et al., 2011; Ring et al., 2018) coupled with the generally lack of available data, the actual emphasis on health traits is therefore often even lower. Key therefore is not just to record more data on health events, but to ensure that data are communicated to the national database for use in genetic evaluations. Moreover, by decomposing (observed) broad health events like mastitis or lameness into their subclinical measures, or even more granular descriptors of the underlying pathogens, some of the random error should be removed thus increasing the heritability - the outcome is a higher accuracy of selection (and thus greater emphasis) for the same number of records, be it traditional genetic evaluations or the now more common genomic evaluations. Technological advances in sensing and associated communication systems have the potential to aid in this shortcoming.

\section{Validation}

Fundamental to the uptake of any technology is sound (ideally independent) evidence that the technology will deliver on promises. Breeding is not exempt from such demands. Ireland is, by far, the most prolific in studies investigating the relationship between genetic merit and subsequent phenotypic performance; this is true of dairy cattle (Ramsbottom et al., 2015; O'Sullivan et al., 2019; Ring et al., 2021), beef (Clarke et al., 1999; McHugh et al., 2014; Connolly et al., 2019; Twomey et al., 2020) and sheep (McHugh et al., 2017, 2020). Validation strategies to demonstrate the merits of breeding include controlled studies (Macdonald et al., 2008; Clarke et al., 2009; Coleman et al., 2009; McCabe et al., 2020) and cross-sectional analysis of either animal-level data (Crews et al., 2006; Connolly et al., 2019; Berry \& Ring, 2020b; 
Twomey et al., 2020) or herd-level data (Ramsbottom et al., 2015; Kelly et al., 2021). Each approach in itself has its own shortcomings, but when consensus is arrived at across all three strategies, then confidence will ensue. Many Irish controlled studies across a range of ruminant species have verified that genotypes of different genetic merit perform differently (Clarke et al., 2009; Coleman et al., 2009; McCabe et al., 2020; Fetherstone et al., 2021); while the extent and depth of measurement in such studies is generally highly precise, and the environmental noise is strongly controlled, such controlled studies can be hampered by a lack of statistical power, a lack of genetic diversity represented, and a caution of extrapolating to production systems not directly represented in the controlled study (hence their general inclusion as fixed effects in the statistical models). Cross-sectional analyses of large databases of individual animal records (Crews et al., 2006; Connolly et al., 2019; Twomey et al., 2020; Ring et al., 2021) do not generally suffer from a lack of statistical power (and thus the likelihood of Type II errors) or genetic diversity, but errors undoubtedly exist within the data; the hope is that the large number of experimental units will lessen the impact of such errors if occurring relatively randomly across genotypes. For example, Purfield et al. (2016) reported a sire parentage error of $13 \%$ in Irish (dairy and beef) cattle, while Berry et al. (2016c) reported an equivalent statistic of $10 \%$ in Irish sheep; because the assigned genetic merit of an animal is dictated, in part, by the sire, such errors undoubtedly influence confidence in the results. Similarly, assignment of animals to the appropriate contemporary group for inclusion in the statistical model is problematic (McHugh et al., 2017). Cross-sectional analyses of large databases of herd-level data (Ramsbottom et al., 2015; Kelly et al., 2021) suffer from similar issues to those of animal-level analyses with the added complication of how to appropriately account for inter-herd differences in technical efficiencies. The statistical approach taken in these studies (Ramsbottom et al., 2015; Kelly et al., 2021) was to attempt to adjust for inter-herd differences in technical efficiency through the adjustment of financial performance metrics for other available measures of technical efficiency such as stocking rate, herd size and concentrate input. While the objective of most such studies is to validate the gains achievable from breeding, also of interest is likely non-linear effects plus any repercussions for other (correlated) traits; the latter is particularly of interest in smaller controlled studies where deeper phenotyping for resource-intensive measures (e.g. feed intake, methane emissions) is possible.

\section{Complementary decision-support tools}

Gains in performance are achieved through a combination of strategic breeding and management decisions. The goal of (herd) breeding programmes is to shift the mean of the distribution of animals in the favourable direction; this can also be achieved by culling the lower performing animals. Decisionsupport tools for dairy (Kelleher et al., 2015) and beef (Dunne et al., 2020b) enterprises have been developed specifically for Ireland to value the expected remaining lifetime profit of each female in a herd. This information can be used to identify mature females for culling but also heifers for graduation into the mature herd (Kelleher et al., 2015; Dunne et al., 2020b). Both tools are built on the principles of selection indexes populated by what are termed production values which are the sum of both the additive genetic merit (used in breeding decisions) and non-additive genetic effects; also considered are non-genetic effects (e.g. permanent environmental effects) as well as other phenotypic factors like cow age and expected calving date. Similar to the national genetic-based breeding decision-support tools, the culling management tools provide the user with a single figure index value; this data-driven metric ultimately provides the user with confidence when making decisions that will have a substantial impact on the performance of the herd. A similar decision tool has been developed to value a calf assuming it is destined for beef production (Dunne et al., 2020a); taken in conjunction with the ranking tool of beef females to identify heifers suitable for the mature herd, comparison of values from both tools can aid in the decision as to the most appropriate fate of a given beef heifer. Such a tool may also be useful in the future to allocate a carbon cost to a given unit of product; while management strategies (e.g. source of energy and protein ingested) contribute to the carbon cost, so too do animal-level features such as days to slaughter and daily feed intake or daily methane output.

Despite lists of males ranked on total merit index being readily available to producers, deciding on which male to mate to which female can become unwieldy, especially in large herds and flocks. Sire mating advice tools are available for suggesting matings between dairy bulls and cows (Carthy et al., 2019), but no such tools exist, in Ireland at least, for suggesting beef bulls matings with either beef females or dairy females; the same is true for sheep. While consideration of coancestry is important in the sire advice systems for dairyon-dairy or beef-on-beef matings, no such worry exists for beef-on-dairy matings (Berry, 2021).

Genetic evaluations work by decomposing the observed phenotype into an additive genetic effect (termed best linear unbiased predictions [BLUPs]) and environmental effects (termed best linear unbiased estimates [BLUEs]). Although focus until recently has been on the BLUP, there is growing interest in the BLUEs for individual herds or flocks and how the response to selection differs by BLUE (Dunne et al., 2019; Kenny et al., 2021). In a study of 1,058 Irish dairy herds, Dunne et al. (2019) reported that when herds were stratified based on their BLUE for milk production, the phenotypic realisation of increasing an animal's genetic merit by 1 unit for milk production was $20 \%$ greater in the herds with the 
best BLUE relative to the worst BLUE herds. Given that BLUEs are routinely generated alongside BLUPs, very little additional computational cost is required to incorporate such information into the decision-support tools currently available. BLUEs have the potential to tailor the estimates of an animal's phenotype based on the environment they will actually be performing in, rather than assuming an average production environment (Dunne et al., 2019; Kenny et al., 2021). Apart from the potential benefit BLUEs offer in tailoring breeding and management decision-support tools (Bastin et al., 2009), BLUEs can also be employed within advisory tools as a metric of the herd's environmental contribution to the overall phenotypic performance. Utilising both BLUEs and BLUPs combined can assist in the identification of potential weakness in the herd/flock, and in doing so, it can lead to the appropriate resolving measures to be put in place.

\section{Knowledge gaps}

Despite considerable research having been completed and deployed, particularly in the past two decades in Ireland, many gaps in knowledge and tools still exist. These include what will constitute the future ruminant breeding objectives and what relative emphasis is on each suite of traits, the most optimal methods for evaluating the genetic merit of animals (i.e. accuracy, speed of calculation), breeding scheme design to ensure long-term genetic gain and finally, the support mechanisms that collapse all the available data and downstream calculations into usable information for producers that can be acted upon.

\section{Future breeding objectives}

Factors dictating whether a trait should be included in future breeding objectives include (Shook, 1989):

- Its importance-importance here was traditionally dictated by monetary value associated with an improvement in the trait; opinion is, however, changing to consider public good type measures with no current monetary reward for improvement.

- Extent of genetic variability - logically without genetic variability, genetic improvement will not be possible. Genetic variation, no matter how small, exists for most traits. It is often incorrectly assumed that a low heritability translates to little genetic variability which may not be the case as a small proportion of a large phenotypic variance still translates to large (exploitable) genetic variability.

- Data availability - individual animal data linked to ancestry and known contributing environmental influences are key to being able to differentiate genetically elite from genetically inferior animals. Although genomic evaluations mitigate the necessity for phenotypic data on an animal itself or its descendants for achieving moderate to high accuracy, phenotypic data are still required on a relatively large population in order to calibrate the prediction equations (Figure 3). The requirement for data on the objective traits themselves can be circumvented by having data on correlated heritable traits, for example, using somatic cell count as a predictor of a clinical mastitis goal trait.

An additional factor which impacts the decision of what trait(s) to focus on for inclusion in a breeding objective is the associated cost-benefit. This is particularly important in light of growing pressures to consider traits associated with the social cost of ruminant production (i.e. use of human-edible energy and protein sources and environmental hoofprint). While there is much interest in improving the efficiency of production through the measure of daily feed intake (Crowley et al., 2010; Berry et al., 2014a, 2014b; Pryce et al., 2015; Hurley et al., 2017), the measurement of such performance traits is resource intensive and a return on investment may not actually be obvious; the same is true for carbon/methane intensity. Faster gains in such metrics may actually be achievable by exploiting more readily available phenotypes such as age at slaughter in terminal animals (Santos et al., 2015; Berry et al., 2017) and lifespan or survival in cows (McHugh et al., 2014; De Vries, 2020; MacNeil et al., 2021; Ring et al., 2021).

While not always explicitly included in breeding objectives, in some instances, much of the variability in (detailed) product quality, efficiency, environmental load, as well as animal health and welfare is already captured via correlated traits. For example, the inclusion of milk output (positive weight) and live weight (negative weight) in the dairy cow EBI is similar to milk solids per kilogram live weight which is correlated with feed conversion efficiency in dairy cows (Hurley et al., 2016). Similarly, residual feed intake is completely captured via its component traits within the Irish beef breeding objectives (Van der Werf, 2004). Although (residual) feed intake is included within the beef and beef-on-dairy breeding objectives, the phenotype is from animals fed indoors; evidence is not clear as to whether this actually translates to feed intake in grazing animals (Lahart et al., 2020) where, in fact, a greater intake capacity may be favourable. No feed intake genetic evaluation currently exists for sheep in Ireland due to a paucity of individual animal phenotypic records. Whereas genetic evaluations exist for milk fat and protein content in dairy cows (Sneddon et al., 2015) and meat organoleptic properties in cattle and sheep (Swan et al., 2015; Berry et al., 2021), the desire for genetic evaluations on more granular measures such as micronutrient content (Soyeurt et al., 2011; de Marchi et al., 2014; Frizzarin et al., 2021) or amenability to easier processing (de Marchi et al., 2014; Visentin et al., 2015) may intensify. Despite the collection of gold standard observations for such traits in large populations of animals for genetic evaluations not being feasible, mid-infrared spectroscopy of milk samples can be 
used to accurately predict such traits (de Marchi et al., 2014; Visentin et al., 2015; McDermott et al., 2016), and genetic evaluations of mid-infrared predicted traits are possible (Bastin et al., 2011; McParland et al., 2015). Similarly, while measures of carcass weight, conformation and fat score are used in cattle and sheep breeding objectives, potential exists to decompose these further into the individual primal cuts (Sarti et al., 2013; Judge et al., 2019), aligning more closely with the downstream processing industry and consumers. Potential may also exist to use non-destructive spectroscopybased approaches to predict meat quality (Herrero, 2008).

As genetic trends for longevity improve in dairy cows (GarcíaRuiz et al., 2016; Berry, 2021), cows are expected to get older. Risk to different ailments including lameness, mastitis and other health problems is known to increase with age (O'Connor et al., 2019) although strategies to mitigate this may be possible, for somatic cell count at least (Williams et al., 2022). Hence, it is likely that the importance of functional conformation and animal health will become more important in the future but also the ability of the mature cow to maintain high performance (and low somatic cell count in the case of dairy cows) with advancing parity (Williams et al., 2022). A similar dilemma exists for beef and sheep.

Environmental traits like methane emissions and nitrogen use efficiency are also likely to grow in importance in the future. Although the acquisition of (accurate) measures for such traits is resource intensive, the costs are incurred by few but the benefits are realised by many. For example, assuming that the output from the Irish dairy, beef and sheep sectors is 8 billion $\mathrm{kg}$ of milk, 550,000 tonnes of beef meat and 55,000 tonnes of sheep meat, then the charge per kilogram output per $€ 1$ million cost of phenotyping animals for a breeding programme would be just $0.013,0.18$ and 1.8 cents, respectively. Methane data are currently being collected in dairy, beef and sheep in Ireland with the anticipation of generating sufficient data for the development of national genetic evaluations as well as identifying the most optimum strategy for recording such data; one example of the latter is the extent of genotype-byenvironment between methane measured indoors on animals fed a mixed ration versus methane measured outdoors in grazing animals.

Developments in agri-tech and the growing accessibility of sensing systems for measuring a whole plethora of metrics (Greenwood et al., 2016) open up opportunities as well as create challenges for future animal breeding programmes. The opportunities include the generation of vast quantities of objective measures not only on the animal itself, but also reflections of the prevailing environmental conditions (for use in the statistical model). Data on non-animal features are also useful in potentially improving the precision of genetic evaluations through the consideration of genotype- by-environment interactions (BLUEs; Dunne et al., 2019). Sensing systems which can be deployed on the animal include those based on accelerometers, magnetometers, gyroscopes, visual, sensors, audio sensors and location sensors as well as equipment to measure temperature, gastrointestinal function, heart rate and respiratory rate (Greenwood et al., 2016; Halachmi et al., 2019). Thermal imaging or actual cameras to measure things in multiple dimensions are feasible. Detailed reviews of the agri-related technologies available are discussed by both Greenwood et al. (2016) and Halachmi et al. (2019). The greatest benefit, however, from such technological advances will be when the vast array of information sources are combined and complemented with available information on ancillary animal and environmental features like animal age, prevailing weather and genetic merit. Of concern, however, is the potential disputes on the ownership of the data and the ability to use these data in national genetic evaluations; this could potentially lead to the development of proprietary genetic evaluations or even genetic evaluations within herds or groups of herds. Such sensing systems will likely have greatest impact for low heritability traits where vast quantities of data are required to achieve accurate predictions of genetic merit but also where combining different data sources including information on influencing systematic environmental effects could contribute to a higher heritability and, by extension, a greater accuracy of selection for the same number of phenotypic records.

Though there is much commentary on agri-tech and its contribution to extensive phenotyping via sensing systems and downstream analytics, the value of (subjective) producerscored data cannot be ignored. Despite being subjective in nature, these traits are clearly heritable (O'Brien et al., 2017; Ring et al., 2018) and constitute a large proportion (i.e. up to $36 \%$ of the emphasis in the breeding objectives) of the relative emphasis of Irish cattle and sheep breeding objectives. Moreover, many are strongly correlated with the goal trait; in an analysis of predicted primal cut data from $>100,000$ carcasses on Irish beef cattle, Pabiou et al. (2012) reported a genetic correlation of 0.49 between farmer-scored weanling quality and the proportion of the eventual carcass of the animal classified as very high-value cuts.

\section{Methodology}

Many genetic evaluations now incorporate genomic information (Pimentel \& Konig, 2012; Meuwissen et al., 2016); the Irish dairy, beef and sheep genomic evaluations all include genomic information. Over-estimation of genetic merit in animals with no performance or progeny information is of growing concern (Koivula et al., 2017). Many possible contributing factors to this bias exist including: (1) there always was bias even in traditional pedigree-based genetic evaluations (e.g. McHugh et al., 2014; Twomey et al., 2020; Ring et al., 2021), (2) 
selective genotyping of animals may occur whereby not all available animals are genotyped, (3) preferential treatment of females in the genotyped reference population may exist, and (4) the small bias per generation culminates over multiple generations before self-correction of the animal through phenotypic data on the animal itself or descendants. Confidence in genomic predictions can be impacted when the realised benefits are less than expected based on published genomic evaluations. Hence, this shortcoming is an area of particular interest (Dassonneville et al., 2012; Koivula et al., 2017). Being able to generate genomic predictions that accurately transfer across generations and breeds is also of particular interest (Olson et al., 2012) especially in Ireland given the large diversity in breeds and their crosses; it is likely that sequence data coupled with advanced computational approaches such as machine learning could help deliver better outcomes (Liu et al., 2019). While phenotypic and genomic data are rapidly amassing on routinely recorded traits, the speed with which data on more difficult-to-measure traits are accumulating is not as fast. Such traits of particular relevance to the modern era are those associated with environmental load, efficiency of feed use, and product quality; these are all difficult-to-measure traits and thus the required dataset sizes to achieve accurate genomic predictions using traditional approaches may not be possible (Figure 3). Algorithms to account for the smaller phenotyped (and genotyped) reference population may also be required especially where (imputed) sequence data are available; procedures for the optimal construction of a small reference population are also important. Finally, the accuracy with which the phenotype of an animal can be predicted based on its additive genetic merit is limited by the narrow-sense heritability (i.e. proportion of phenotypic variance attributable to additive genetic effects). Being able to predict non-additive genetic effects (i.e. intraand inter-locus effects) would be advantageous in improving the predictive ability of performance from genomic information with the benefits realised in decision-support tools.

\section{Breeding schemes}

The ruminant breeding schemes in Ireland (e.g. McParland et al., 2009) do not actively exploit recent advances in reproductive technologies (with the exception of $\mathrm{Al}$ ). Four pathways contribute to genetic gain (Robertson \& Rendel, 1950): sires to produce sires (i.e. bulls/rams to sire the next generation of elite $[\mathrm{Al}]$ bulls/rams), sires to produce dams (i.e. Al and natural mating bulls/rams used by producers to generate female replacements), dams to produce sires (i.e. elite cows/ewes to produce the next generation of young elite [Al] bulls/rams) and dams to produce dams (i.e. cows/ewes in commercial herds). Much of the genetic gain currently achieved is in the sire to produce progeny pathways; simulating an efficient dairy cattle breeding programme,
Schaeffer (2006) documented how over $80 \%$ of annual genetic gain in such a breeding programme is achieved via the sire to produce progeny pathways. Much of the further genetic gain will therefore likely be achieved through the dam to produce offspring pathways; this can be realised through a combination of improved selection intensity and reduced generation interval with the improvement in accuracy of selection being achieved mainly through genomic evaluations although more extensive phenotyping, especially as heifers/ewe lambs, could improve the accuracy of selection further. Accurate data collection on individual candidate dams has huge potential to increase the accuracy of selection, especially for high heritability traits. By its very nature, more accurate data collection is likely to be less influenced by random noise, thus possibly contributing to an even higher heritability in itself. Accurate phenotypic data could also, of course, imply deeper phenotyping. One example is the interval from calving to the commencement of luteal activity versus the interval from calving to first service. From a review of the cattle literature, Berry et al. (2014b) reported a mean heritability of 0.149 for the interval to commencement of luteal activity versus a mean of 0.052 for the interval to first service; some of the observed difference could be due to less accurate recording of the latter (e.g. missed oestrus) but also conscious decisions by the producer not to serve a cow even though she was on oestrus. The same principles would exist for activity meters on females. For mass selection, where the animal is selected on the basis of its own phenotype, the accuracy of selection is the square root of the heritability; so, for example, based on a heritability of 0.35 (e.g. milk yield), the accuracy of selection on a single record from an individual would be 0.59 (i.e. $\sqrt{0.35}$ ); assuming a repeatability of 0.50 (e.g. milk yield), the accuracy of selection for an animal with two or three records would be 0.68 and 0.73 , respectively. Moreover, not only would such information on individual females be useful for breeding purposes but it also can have considerable use in day-to-day management decisions.

Opportunities to improve selection intensity in cattle in particular include the use of targeted sexed semen and embryo production. Sexed semen can contribute to genetic gain through increasing selection intensity by only needing to mate a proportion of the genetically elite females in the herd/ flock to generate replacements (Sørensen et al., 2011). The mean of the top $25 \%$ of females in a herd/flock is $2.54 \mathrm{s.d}$. units higher than the mean of the top $75 \%$ of females in the herd/flock; based on mean s.d. across Irish dairy and beef herds of $€ 32$ (25,549 herd-year between 2016 and 2018) and $€ 25$ (56,756 herd-years between 2016 and 2018) for the dairy and beef replacement index, this equates to a difference in the respective index between the top $25 \%$ and top $75 \%$ of $€ 81$ and $€ 64$, respectively. All else being equal, this should increase the rate of genetic gain from this pathway by the same amount and that of the entire population (assuming 
no changes to other selection pathways) by $11 \%$ using the population parameters reported by Schaeffer (2006) for dairy cows. These selected females who become parents of the next generation will also tend to be the younger females (i.e. heifers and ewe lambs); this will contribute to an additional benefit in reducing the generation interval. Combined, the increased selection intensity and a reduction in generation interval of the dam to produce dam selection pathway by $1 \mathrm{yr}$ could accelerate genetic gain by a factor of 1.24 over and above the status quo.

Selection intensity and generation interval can also be improved, particularly in the dams to produce sires selection pathway, with embryo production coupled with genomic selection of the generated embryos. Traditional strategies of multiple ovulation embryo transfer are now being replaced by ovum pick-up combined with in vitro embryo production (OPU-IVP; Pontes et al., 2011); efficient procedures now exist to generate high-quality implantable embryos without the necessity for any hormonal treatment of either the donor or the recipient. One of the main bottlenecks and costs of such breeding schemes are those associated with the recipients. Carefully selecting the implanted embryos based on their genotype can increase the intensity of selection further and reduce the requirement for recipient females. Nonetheless, as selection intensity in particular improves with the exploitation of such reproductive technologies, the risk of inbreeding also intensifies. Genome-derived inter-animal relationships can, however, help mitigate against rapidly accumulating inbreeding. More importantly, genomics can also help focus on the location of homozygosity in the genome and its impact, if any, on subsequent performance (Pryce et al., 2014); this is because inbreeding is unlikely to have an impact on regions of the genome not controlling performance. Several lethal mutations have, for example, been discovered (Cole et al., 2016; Braiek et al., 2021), so caution should be taken when mating carriers. Moreover, given the impact of climate change on weather conditions (and downstream effects like exposure of naive populations to exotic organisms), maintenance of genetic diversity will be key to ensure a robust population; inbreeding erodes genetic diversity.

Although developments in reproductive technologies enable faster genetic gain in the female to progeny pathway, it also provides opportunities to be more selective in the sires used on the females not chosen to be parents of the next generation. Dairying in particular can reap the benefits of increasing the value of calves through the use of beef bulls on the dairy females (Berry \& Ring, 2020b) exploiting tools like a dairy-beef index (Fogh, 2016; Berry et al., 2019) to identify such sires. The same is true for beef cows in that sires with more terminal characteristics can be mated to females not destined to become parents of the next generation. Care, however, should be taken of any likely increase in the risk of calving dystocia
(Berry \& Ring, 2020b) but also the potential impact of beef sires on subsequent dairy cow performance even in the absence of any degree of calving difficulty (Berry \& Ring, 2020a).

\section{Decision support}

Developments in sensing systems and their use in agriculture will naturally lead to increased volume, velocity, variety, veracity and value (i.e. big data). Decomposing these data into value-creating decision-support tools with crosscompatibility across other such tools will be a major challenge; greater interaction with end-user focus groups will be of utmost importance to ensure that the tool is not only fit for purpose but also reaps a sufficient return on investment for all actors. Artificial intelligence will undoubtedly contribute to the analytical systems underpinning such tools; explainable artificial intelligence (XAI) systems will also have a major role in demonstrating how the solutions have been arrived at and thus can be readily understood (and therefore more accepted) by the end user. It is also likely that more use will be made of federated learning to deal with heterogenous data sources while preserving privacy and security of the data owners.

Whereas many decision-support tools, especially those based on mating advice, tend to predict the expected mean performance, the variability in predictions of the associated risk will also become important. For example, in the development of a sire mating advice system for mating dairy bulls to dairy females, Carthy et al. (2019) predicted the expected progeny merit for the different combinations of male-female matings. With growing access to genomic information, however, it is possible to accurately construct the phased haplotypes of all animals. Such knowledge can be used to calculate the expected variance in progeny genotype (Santos et al., 2019) which can then be used to generate the distribution in expected (total or additive) genetic merit for all evaluated traits (and overall breeding objective). Such a tool could be particularly useful in establishing the risk of calving dystocia for a given mating, especially for beef-on-dairy matings (Berry, 2021). In such circumstances, dairy producers may opt for bulls with a slightly greater mean predisposition to calving difficulty but with a greater likelihood of producing more homogenous calves and thus fewer very large calves which may require veterinary intervention during calving. Growing information on genetic variants with large effects including those associated with infertility (Cole et al., 2016) will also play a pivotal role not only in mating advice programmes but also in personalised management systems.

Personalised management is where the management is optimised to the genotype of the individual. While often heralded as the future, the practice of personalised management or nutrition is well established; a good example of such is the different feeding management in late gestation sheep depending on the number of lambs in utero or indeed the differential in 
feeding levels and dry length period of cows differing in body condition score. However, generation of predisposition metrics (called polygenic scores in the human sciences; Torkamani et al., 2018), which incorporate both genetic and non-genetic features coupled with more automation on farms, will make personalised management more achievable. Prediction of genetic merit for certain traits can also influence decision rules used in decision-support tools, implying that the decision process is bespoke to the animal. For example, a somatic cell count in dairy cows of $>200,000$ cells $/ \mathrm{mL}$ may cause an alert in primiparous cows, but this threshold may lowered to $>150,000$ if the cow in question is known to have genetic predisposition to mastitis; this is akin to patients being asked about family history of certain diseases by doctors when trying to more accurately diagnose ailments. Decision-support tools and personalised management can, however, complicate genetic evaluations. Such personalised management may involve feeding to yield thereby impacting the foundational assumptions of a contemporary group; another example could be the prediction of likely mastitis in which case the producer may try to advert a clinical case and, if successful, no mastitis event will enter the database for use in genetic evaluations. Such personalised management could also be at the level of the herd exploiting herd BLUEs to tailor not only the breeding goal to the herd but also the expected response to selection for each trait given the herd BLUE for that trait (Craig et al., 2018; Dunne et al., 2019; Kenny et al., 2021).

\section{Conclusions}

The key steps of a successful animal breeding programmes include: (1) a pertinent and relevant breeding goal, (2) the appropriate breeding objective underpinned by a selection index with sufficient high-quality data from the relevant population (and production systems), (3) an accurate genetic/ genomic evaluation system, (4) an efficient and effective breeding scheme, and (5) a system to disseminate the elite germplasm to the end user; validation of genetic evaluations and breeding objectives is also key. While the current national breeding objectives in Ireland are extensive, suites of traits that will need to be considered more in future ruminant breeding objectives include environmental impact, product quality and animal well-being. Research on how best to incorporate such traits (i.e. phenotyping strategy, genetic evaluations, weighting factors) is underway.

\section{References}

Bastin, C., Laloux, L., Gillon, A., Miglior, F., Soyeurt, H., Hammami, H., Bertozzi, C. and Gengler, N. 2009. Modeling milk urea of Walloon dairy cows in management perspectives. Journal of Dairy Science 92: 3529-3540.

Bastin, C., Gengler, N. and Soyeurt, H. 2011. Phenotypic and genetic variability of production traits and milk fatty acid contents across days in milk for Walloon Holstein first-parity cows. Journal of Dairy Science 94: 4152-4163.

Berry, D.P. 2018. Breeding a better cow-will she be adaptable? Journal of Dairy Science 101: 3665-3685.

Berry, D.P. 2021. Beef-on-dairy - the generation of crossbred beef $\times$ dairy cattle. Journal of Dairy Science. 104: 3789-3819.

Berry, D.P. and Ring, S.C. 2020a. The beef merit of the sire mated to a dairy female impacts her subsequent performance. Journal of Dairy Science 103: 8241-8250.

Berry, D.P. and Ring, S.C. 2020b. Observed progeny performance validates the benefit of mating genetically elite beef sires to dairy females. Journal of Dairy Science 103: 2523-2533.

Berry, D.P., Shalloo, L., Cromie, A.R., Veerkamp, R.F., Dillon, P., Amer, P.R., Kearney, J.F., Evans, R.D. and Wickham, B. 2007. "The Economic Breeding Index: A Generation on". Irish Cattle Breeding Federation, Bandon, Ireland.

Berry, D.P., Kearney, F. and Harris, B. 2009. Genomic selection in Ireland. Proceedings of the Interbull International Workshop: Genomic Information in Genetic Evaluations, Uppsala, Sweden, 26 January 2009, Bulletin No. 39, pages 29-34.

Berry, D.P., Bermingham, M.L., Good, M. and More, S.J. 2011. Genetics of animal health and disease in cattle. Irish Veterinary Journal 64: 5.

Berry, D.P., Coffey, M.P., Pryce, J.E., de Haas, Y., Lovendahl, P., Krattenmacher, N., Crowley, J.J., Zang, Z., Spurlock, D., Weigel, K., Macdonald, K. and Veerkamp, R.F. 2014a. International genetic evaluations for feed intake in dairy cattle through the collation of data from multiple sources. Journal of Dairy Science 97: 3894-3905.

Berry, D.P., Wall, E. and Pryce, J.E. 2014b. Genetics and genomics of reproductive performance in dairy and beef cattle. Animal 8: 105-121.

Berry, D.P., Friggens, N.C., Lucy, M. and Roche, J.R. 2016a. Milk production and fertility in cattle. Annual Reviews Animal Biosciences 4: 269-290.

Berry, D.P., Garcia, J.F. and Garrick, D.J. 2016b. Development and implementation of genomic predictions in beef cattle. Animal Frontiers 6: 32-38.

Berry, D.P., O'Brien, A., Wall, E., McDermott, K., Randles, S., Flynn, P., Park, S., Grose, J., Weld, R. and McHugh, N. 2016c. Inter-and intra-reproducibility of genotypes from sheep technical replicates on Illumina and Affymetrix platforms. Genetics Selection Evolution 48: 86.

Berry, D.P., Cromie, A.R. and Judge, M.M. 2017. Rapid Communication: large exploitable genetic variability exists to shorten age at slaughter in cattle. Journal of Animal Science 95: 4526-4532.

Berry, D.P., Amer, P.R., Evans, R.D., Byrne, T., Cromie, A.R. and Hely, F. 2019. A breeding index to rank beef bulls for use on dairy females to maximize profit. Journal of Dairy Science 102: 10056-10072. 
Berry, D.P., Conroy, S., Hegarty, P.J., Evans, R.D., Pabiou, T. and Judge, M.M. 2021. Inter-animal genetic variability exist in organoleptic properties of prime beef meat. Meat Science 173: 108401.

Bjelland, D.W., Weigel, K.A., Vukasinovic, N. and Nkrumah, J.D. 2013. Evaluation of inbreeding depression in Holstein cattle using whole-genome SNP markers and alternative measures of genomic inbreeding. Journal of Dairy Science 96: 4697-4706.

Boichard, D., Chung, H., Dassonneville, R., David, X., Eggen, A., Fritz, S., Gietzen, K.J., Hayes, B., Lawley, C.T., Sonstegard, T.S., Van Tassell, C.P., VanRaden, P.M., Viaud-Martinez, K.A. and Wiggans, G.R. 2012. Design of a bovine low-density SNP array optimized for imputation. PLoS One 7: e34130.

Braiek, M.B., Fabre, S., Hozé, C., Astruc, J.-M. and Moreno-Romieux, C. 2021. Identification of homozygous haplotypes carrying putative recessive lethal mutations that compromise fertility traits in French Lacaune dairy sheep. Genetics Selection Evolution 53: 41.

Carthy, T.R., McCarthy, J. and Berry, D.P. 2019. A mating advice system in dairy cattle incorporating genomic information. Journal of Dairy Science 102: 8210-8220.

Clarke, A.M., Drennan, M.J., McGee, M., Kenny, D.A., Evans, R.D. and Berry, D.P. 2009. Intake, growth and carcass traits in male progeny of sires differing in genetic merit for beef production. Animal 3: 791-801.

Cole, J.B., Null, D.J. and VanRaden, P.M. 2016. Phenotypic and genetic effects of recessive haplotypes on yield, longevity, and fertility. Journal of Dairy Science 99: 7274-7288.

Coleman, J., Pierce, K.M., Berry, D.P., Brennan, A. and Horan, B. 2009. The influence of genetic selection and feed system on the reproductive performance of spring-calving dairy cows within future pasture-based production systems. Journal of Dairy Science 92: 5258-5269.

Connolly, S.M., Cromie, A.R., Sleator, R.D. and Berry, D.P. 2019. Predicted carcass meat yield and primal cut yields in cattle divergent in genetic merit for a terminal index. Translational Animal Science 3: 1-13.

Craig, H.J.B., Stachowicz, K., Black, M., Parry, M., Burke, C., Meier, S. and Amer, P.R. 2018. Genotype by environment interactions in fertility traits in New Zealand dairy cows. Journal of Dairy Science 101: 10991-11003.

Crews, D.H., Carstens, G.E. and Lancaster, P.A. Jr. 2006. A multiple trait selection index including feed efficiency. Professional Animal Scientist 22: 65-70.

Crowley, J.J., McGee, M., Kenny, D.A., Crews Jr, D.H., Evans, R.D. and Berry, D.P. 2010. Phenotypic and genetic parameters for different measures of feed efficiency in different breeds of Irish performance tested beef bulls. Journal of Animal Science 88: 885-894.

Dassonneville, R., Baur, A., Fritz, S., Boichard, D. and Ducrocq, V. 2012. Inclusion of cow records in genomic evaluations and impact on bias due to preferential treatment. Genetics Selection Evolution 44: 40.
De Marchi, M., Toffanin, V., Cassandro, M. and Penasa, M. 2014. Invited review: mid-infrared spectroscopy as a phenotyping tool for milk traits. Journal of Dairy Science 97: 1171-1186.

De Vries, A. 2020. Why revisit dairy cattle productive lifespan? Journal of Dairy Science 103: 3838-3845.

Dunne, F.L., McParland, S., Kelleher, M.M., Walsh, S.W. and Berry, D.P. 2019. How herd best linear unbiased estimates affect the progress achievable from gains in additive and nonadditive genetic merit. Journal of Dairy Science 102: 5295-5304.

Dunne, F.L., Evans, R.D., Kelleher, M.M., Walsh, S.W. and Berry, D.P. 2020a. Formulation of a decision support tool incorporating both genetic and non-genetic effects to rank young growing cattle on expected market value. Animal 15: 100077.

Dunne, F.L., Berry, D.P., Kelleher, M.M., Evans, R.D., Walsh, S.W. and Amer, P.R. 2020b. An index framework founded on the future profit potential of female beef cattle to aid the identification of candidates for culling. Journal of Animal Science 98: $1-14$.

Fetherstone, N., McHugh, N., Boland, T.M. and McGovern, F.M. 2021. The impact of maternal genetic merit and country of origin on ewe reproductive performance, lambing performance and ewe survival. Translational Animal Science $\mathbf{5}$

Fogh, A. 2016. "Description of the X-Index". SEGES, Aarhus, Denmark.

Frizzarin, M., Gormley, I.C., Berry, D.P., Murphy, T.B., Casa, A., Lynch, A. and McParland, S. 2021. Predicting cow milk quality traits from routinely available milk spectra using statistical machine learning methods. Journal of Dairy Science 104: 7438-7447.

García-Ruiz, A., Cole, J.B., VanRaden, P.M., Wiggans, G.R., RuizLópez, F.J. and Van Tassell, C.P. 2016. Changes in genetic selection differentials and generation intervals in US Holstein dairy cattle as a result of genomic selection. Proceedings of the National Academy of Science USA 113: E3995-E4004.

Greenwood, P.L., Bishop-Hurley, G.J., González, L.A. and Ingham, A.B. 2016. Development and application of a livestock phenomics platform to enhance productivity and efficiency at pasture. Animal Production Science 56: 1299-1311.

Halachmi, I., Guarino, M., Bewley, J., and Pastell, M. 2019. Smart animal agriculture: application of real-time sensors to improve animal well-being and production. Annual Review of Animal Biosciences 7: 403-425.

Havenstein, G.B., Ferket, P.R. and Qureshi, M.A. 2003. Growth, livability, and feed conversion of 1957 versus 2001 broilers when fed representative 1957 and 2001 broiler diets. Poultry Science 82: 1500-1508.

Hazel, L.N. 1943. The genetic basis for constructing selection indexes. Genetics 28: 476.

Henderson, C.R. 1950. Estimation of genetic parameters. Annals of Mathematics and Statistics 21: 309-310.

Herrero, A.M. 2008. Raman spectroscopy a promising technique for quality assessment of meat and fish: a review. Food Chemistry 107: 1642-1651. 
Hurley, A.M., Lopez-Villalobos, N., McParland, S., Kennedy, E., Lewis, E., O'Donovan, M., Burke, J.L. and Berry, D.P. 2016. Inter-relationships among alternative definitions of feed efficiency in grazing lactating dairy cows. Journal of Dairy Science 99: 468-479.

Hurley, A.M., Lopez-Villalobos, N., McParland, S., Lewis, E., Kennedy, E., O'Donovan, M., Burke, P. and Berry, D.P. 2017. Genetics of alternative definitions of feed efficiency in grazing lactating dairy cows. Journal of Dairy Science 100: 5501-5514.

Judge, M.M., Kearney, J.F., McClure, M.C., Sleator, R.D. and Berry, D.P. 2016. Evaluation of developed low-density genotype panels for imputation to higher density in independent dairy and beef cattle populations. Journal of Animal Science 94: 949-962.

Judge, M.M., Pabiou, T., Murphy, J., Conroy, S.B., Hegarty, P.J. and Berry, D.P. 2019. Potential exists to change, through breeding, the yield of individual primal carcass cuts in cattle without increasing overall carcass weight. Journal of Animal Science 97: 2769-2779.

Kelleher, M.M., Amer, P.R., Shalloo, L., Evans, R.D., Byrne, T.J., Buckley, F. and Berry, D.P. 2015. Development of an index to rank dairy females on expected lifetime profit. Journal of Dairy Science 98: 4225-4239.

Kelly, D.N., Connolly, K., Kelly, P., Cromie, A.R., Murphy, C.P., Sleator, R.D. and Berry, D.P. 2021. Commercial beef farms excelling in herd terminal and maternal genetic merit generate more profit. Translational Animal Science $\mathbf{5}$.

Kenny, D.A., Sleator, R.D., Murphy, C.P., Evans, R.D. and Berry, D.P. 2021. Herd best linear unbiased estimates (BLUEs) can be used as a tool to rescale the expected expression of genetic potential in cattle. Journal of Animal Breeding and Genetics 138: 655-667.

Koivula, M., Strandén, I., Aamand, G.P. and Mäntysaari, E.A. 2017. Reducing bias in the dairy cattle single-step genomic evaluation by ignoring bulls without progeny. Journal of Animal Breeding and Genetics 135: 107-115.

Lahart, B., Prendiville, R., Buckley, F., Kennedy, E., Conroy, S.B., Boland, T.M. and McGee, M. 2020. The repeatability of feed intake and feed efficiency in beef cattle offered high-concentrate, grass silage and pasture-based diets. Animal 14: 2288-2297.

Liu, A., Lund, M.S., Boichard, D., Karaman, E., Fritz, S., Aamand, G.P., Sander Nielsen, U., Wang, Y. and Su, G. 2019. Improvement of genomic prediction by integrating additional single nucleotide polymorphisms selected from imputed whole genome sequencing data. Heredity 124: 37-49.

Lopez-Villalobos, N. and Garric, D.J. 2005. Methodology for the design and enhancement of genetic improvement programs illustrated in the context of the New Zealand dairy industry. Agroceniencia IX: 553-558.

Lucy, M.C. 2001. Reproductive loss in high-producing dairy cattle: where will it end? Journal of Dairy Science 84: 1277-93.

Macdonald, K.A., Verkerk, G.A., Thorrold, B.S., Pryce, J.E., Penno, J.W., McNaughton, L.R., Burton, L.J., Lancaster, J.A.S., Williamson, J.H. and Holmes, C.W. 2008. A comparison of three strains of
Holstein-Friesian grazed on pasture and managed under different feed allowances. Journal of Dairy Science 91: 1693-1707.

MacNeil, M.D., Buchanan, J.W., Spangler, M.L., Hamidi Hay, E. 2021. Effects of management decisions on genetic evaluation of simulated calving records using random regression. Translational Animal Science 5: txab078.

Marina, H., Chitneedi, P., Pelayo, R., Suárez-Vega, A., EstebanBlanco, C., Gutiérrez-Gil, B. and Arranz, J.J. 2021. Study on the concordance between different SNP-genotyping platforms in sheep. Animal Genetics 52: 868-880.

McCabe, S., McHugh, N., O'Connell, N.E. and Prendiville, R. 2020. Evaluation of production efficiencies at pasture of lactating suckler cows of diverse genetic merit and replacement strategy. Animal 14: 1768-1776.

McClure, M.C., Sonstegard, T.S., Wiggans, G.R., Van Eenennaam, A.L., Weber, K.L., Penedo, C.T., Berry, D.P., Flynn, J., Garcia, J., Carmo, A.S., Regitano, L.C.A., Albuquerque, M., Silva, M.V.G.B., Machado, M.A., Coffey, M., Moore, K., Boscher, M.Y., Genestout, L., Mazza, R., Taylor, J., Schnabel, R., Simpson, B., Marques, E., McEwan, J., Cromie, A., Coutinho, L., Kuehn, L., Keele, J., Piper, E., Cook, J., Williams, R. and Van Tassell, C. 2013. Imputation of microsatellite alleles from dense SNP genotypes for parentage verification across multiple Bos taurus and Bos indicus breeds. Frontiers in Genetics 4: 1-11.

McDermott, A., Visentin, G., De Marchi, M., Berry, D.P., Fenelon, M.A., O'Connor, P.M., Kenny, O.A. and McParland, S. 2016. Prediction of individual milk proteins including free amino acids in bovine milk using mid-infrared spectroscopy and their correlations with milk processing characteristics. Journal of Dairy Science 99: 3171-3182.

McHugh, N., Cromie, A.R., Evans, R.D. and Berry, D.P. 2014. Validation of national genetic evaluations for maternal beef cattle traits using Irish field data. Journal of Animal Science 92: 1423-1432.

McHugh, N., Pabiou, T., Wall, E., McDermott, K. and Berry, D.P. 2017. Impact of alternative definitions of contemporary groups on genetic evaluations of traits recorded at lambing. Journal of Animal Science 95: 1926-1938.

McHugh, N., Pabiou, T., Wall, E., McDermott, K. and Berry, D.P. 2020. Considerable potential exists to improve lambing performance traits in sheep through breeding. Livestock Science 235: 104007.

McParland, S., Kearney, J.F., Rath, M. and Berry, D.P. 2007. Inbreeding effects on milk production, calving performance, fertility, and conformation in Irish Holstein-Friesians. Journal of Dairy Science 90: 4411-4419.

McParland, S., Kearney, J.F., MacHugh, D.E. and Berry, D.P. 2008. Inbreeding effects on postweaning production traits, conformation, and calving performance in Irish beef cattle. Journal of Dairy Science 86: 3338-3347.

McParland, S., Kearney, J.F., Lopez-Villalobos, N. and Berry, D.P. 2009. Optimal system of contract matings for use in a commercial population. Irish Journal of Agricultural \& Food Research 48: 43-56. 
McParland, S., Kennedy, E., Lewis, E., Moore, S.G., McCarthy, B., O'Donovan, M. and Berry, D.P. 2015. Genetic parameters of dairy cow energy intake and body energy status predicted using mid-infrared spectrometry of milk. Journal of Dairy Science $\mathbf{9 8}$ : 1310-1320.

Meuwissen, T.H.E., Hayes, B.J. and Goddard, M.E. 2001. Prediction of total genetic value using genome-wide dense marker maps. Genetics 157: 1819-1829.

Meuwissen, T.H.E., Hayes, B.J. and Goddard, M.E. 2016. Genomic selection: a paradigm shift in animal breeding. Animal Frontiers 6: 6-14.

Mullen, M.P., McClure, M.C., Kearney, J.F., Waters, S.M., Weld, R., Flynn, P., Creevev, C., Cromie, A.R. and Berry, D.P. 2013. Development of a custom SNP chip for dairy and beef cattle breeding, parentage and research. Proceedings of the Interbull Meeting, Nantes.

O'Brien, A.C., McHugh, N., Wall, E., Pabiou, T., McDermott, K., Randles, S., Fair, S. and Berry, D.P. 2017. Genetic parameters for lameness, mastitis and dagginess in a multi-breed sheep population. Animal 11: 911-919.

O'Connor, A.H., Bokkers, E.A.M., de Boer, I.J.M., Hogeveen, H., Sayers, R., Byrne, N., Ruelle, E. and Shalloo, L. 2019. Associating cow characteristics with mobility scores in pasture-based dairy cows. Journal of Dairy Science 102: 8332-8342.

Olson, K.M., VanRaden, P.M. and Tooker, M.E. 2012. Multibreed genomic evaluations using purebred Holsteins, Jerseys, and Brown Swiss. Journal of Dairy Science 95: 5378-5383.

O'Sullivan, M., Horan, B., Pierce, K.M., McParland, S., O'Sullivan, K. and Buckley, F. 2019. Milk production of Holstein-Friesian cows of divergent Economic Breeding Index evaluated under seasonal pasture-based management. Journal of Dairy Science 102: 2560-2577.

Pabiou, T., Fikse, W.F., Amer, P.R., Cromie, A.R., Nasholm, A. and Berry, D.P. 2012. Genetic relationships between carcass cut weights predicted from video image analysis and other performance traits in cattle. Animal 6: 1389-1399.

Pimentel, E.C.G. and König, S. 2012. Genomic selection for the improvement of meat quality in beef. Journal of Animal Science 90: 3418-3426.

Pontes, J.H.F., Melo Sterza, F.A., Basso, A.C., Ferreira, C.R., Sanches, B.V., Rubin, K.C.P. and Seneda, M.M. 2011. Ovum pick up, in vitro embryo production, and pregnancy rates from a large-scale commercial program using Nelore cattle (Bos indicus) donors. Theriogenology 75: 1640-1646.

Pryce, J.E., Veerkamp, R.F., Thompson, R., Hill, W.G. and Simm, G. 1997. Genetic aspects of common health disorders and measures of fertility in Holstein Friesian dairy cattle. Animal Science 65: 353-360.

Pryce, J.E., Haile-Mariam, M., Goddard, M.E. and Hayes, B.J. 2014. Identification of genomic regions associated with inbreeding depression in Holstein and Jersey dairy cattle. Genetics Selection Evolution 46: 71

Pryce, J.E., Gonzalez-Recio, O., Nieuwhof, G., Wales, W.J., Coffey, M.P., Hayes, B.J. and Goddard, M.E. 2015. Definition and implementation of a breeding value for feed efficiency in dairy cows. Journal of Dairy Science 98: 7340-7350.

Purfield, D., McClure, M. and Berry, D.P. 2016. Justification for setting the individual animal genotype call rate threshold at eighty-five percent. Journal of Animal Science 94: 4558-4569.

Ramsbottom, G., Horan, B., Berry, D.P. and Roche, J.R. 2015. Factors associated with the financial performance of spring-calving, pasturebased dairy farms. Journal of Dairy Science 98: 3526-3540.

Rendel, J. and Robertson, A. 1950. Estimation of genetic gain in milk yield by selection in a closed herd of dairy cattle. Journal of Genetics 50: 1-8.

Ring, S.C., Twomey, A.J., Byrne, N., Kelleher, M.M., Pabiou, T., Doherty, M. and Berry, D.P. 2018. Genetic selection for hoof health traits and cow mobility scores can accelerate the rate of genetic gain in producer-scored lameness in dairy cows. Journal of Dairy Science 101: 10034-10047.

Ring, S.C., Purfield, D.C., Good, M., Breslin, P., Ryan, E., Blom, A., Evans, R.D., Doherty, M.L., Bradley, D.G. and Berry, D.P. 2019. Variance components for bovine tuberculosis infection and multibreed genome-wide association analysis using imputed whole genome sequence data. PLoS One 14: e0212067.

Ring, S.C., Evans, R.D., Cromie, A.R. and Berry, D.P. 2021. Crosssectional analyses of national database confirms superior genetic merit translates to superior dairy cow performance. Journal of Dairy Science 104: 8076-8093.

Robertson, A. and Rendel, J.M. 1950. The use of progeny testing with artificial insemination in dairy cattle. Journal of Genetics $\mathbf{5 0}$ : 21-31.

Santos, D.J.A., McHugh, N., Byrne, T., Berry, D.P. and Amer, P.R. 2015. Comparison of breeding objectives across countries with application to sheep indexes in New Zealand and Ireland. Journal of Animal Breeding and Genetics 132: 144-154.

Santos, D.J.A., Cole, J.B., Lawlor, T.J., VanRaden, P.M., Tonhati, H. and Ma, L. 2019. Variance of gametic diversity and its application in selection programs. Journal of Dairy Science 102: 5279-5294.

Sarti, F.M., Pieramati, C., Lubricchio, E., Giontella, A., Lasagna, E. and Panella, F. 2013. Genetic parameters for the weights and yields of carcass cuts in chianina cattle. Journal of Animal Science 91: 4099-4103.

Sayers, R.G. 2017. Associations between exposure to bovine herpesvirus 1 (BoHV-1) and milk production, reproductive performance, and mortality in Irish dairy herds. Journal of Dairy Science 100: 1340-1352.

Schaeffer, L.R. 2006. Strategy for applying genome-wide selection in dairy cattle. Journal of Animal Breeding and Genetics 123: 218-223.

Shook, G.E. 1989. Selection for disease resistance. Journal of Dairy Science 72: 1349-1362.

Sneddon, N.W., Lopez-Villalobos, N., Davis, S.R., Hickson, R.E. and Shalloo, L. 2015. Genetic parameters for milk components including lactose from test day records in the New Zealand dairy herd. New Zealand Journal of Agricultural Research 58 97-107. 
Sørensen, M.K., Voergaard, J., Pedersen, L.D., Berg, P. and Sørensen, A.C. 2011. Genetic gain in dairy cattle populations is increased using sexed semen in commercial herds. Journal of Animal Breeding and Genetics 128: 267-275.

Soyeurt, H., Dehareng, F., Gengler, N., McParland, S., Wall, E., Berry, D.P. and Coffey, M. 2011. Mid-infrared prediction of bovine milk fatty acids across multiple breeds, production systems, and countries. Journal of Dairy Science 94: 1657-1667.

Swan, A., Pleasants, T. and Pethick, D. 2015. Breeding to improve meat eating quality in Terminal sire sheep breeds. 21st Conference of the Association for the Advancement of Animal Breeding and Genetics, 28-30 September 2015, Lorne, Victoria.

Torkamani, A., Wineinger, N.E. and Topol, E.J. 2018. The personal and clinical utility of polygenic risk scores. Nature Reviews Genetics. 19: 581-590.

Twomey, A.J., Sayers, R.G., Carroll, R.I., Byrne, N., Brien, E.O., Doherty, M.L., McClure, J.C., Graham, D.A. and Berry, D.P. 2016. Genetic parameters for both a liver damage phenotype caused by and antibody response to phenotype in dairy and beef cattle. Journal of Animal Science 94: 4109-4119.

Twomey, A.J., Cromie, A.R., McHugh, N. and Berry, D.P. 2020. Validation of a beef cattle maternal breeding objective based on a cross-sectional analysis of a large national cattle database. Journal of Animal Science 98: skaa322.

Van der Werf, J.H.J. 2004. Is it useful to define residual feed intake as a trait in animal breeding programmes? Australian Journal of Experimental Agriculture 44: 405-409.

Visscher, P.M., Hill, W.G. and Wray, N.R. 2008. Heritability in the genomics era: concepts and mis-conceptions. Nature Reviews Genetics 9: 255-266.

Visentin, G., McDermott, A., McParland, S., Berry, D.P., Kenny, O.A., Brodkorb, A., Fenelon, M.A. and De Marchi, M. 2015. Prediction of bovine milk technological traits from mid-infrared spectroscopy analysis in dairy cows. Journal of Dairy Science $\mathbf{9 8}$ : 6620-6629.

Wickham, B.W., Amer, P.R., Berry, D.P., Burke, M., Coughlan, S., Cromie, A., Kearney, J.F., McHugh, N., McParland, S. and O'Connell, K. 2012. Industrial perspective: capturing the benefits of genomics to Irish cattle breeding. Animal Production Science $\mathbf{5 2}$ : 172-179.

Williams, M., Sleator, R.D., Murphy, C.P., McCarthy, J. and Berry, D.P. 2022. Exploiting genetic variability in the trajectory of lactation yield and somatic cell score with each progressing parity. Journal of Dairy Science. https://doi.org/10.3168/jds.2021-21306. 